\title{
A Corpus-driven Analysis of the Uses of English Polarity Expressions between Native Speakers and Chinese Learners
}

\author{
Huanqi Ji (Corresponding author) \& Xie Zhang \\ School of Literature and Law, Sichuan Agricultural University \\ No. 46 Xinkang Road, Ya'an 625014, Sichuan, China \\ Tel: 86-835-223-8211Ｅ-mail: joe0919@126.com
}

Received: December 18, 2011

Accepted: January 30, $2012 \quad$ Published: April 1, 2012

doi:10.5539/ijel.v2n2p149

URL: http://dx.doi.org/10.5539/ijel.v2n2p149

The research is financed by the Social and Philosophic Academic Program of Sichuan Agricultural University No. SICAU02800145

\begin{abstract}
This paper briefly introduces the Open Choice Principle, the Idiom Principle and the Affective-polarity Theory to suggest that language use is not as random as it is assumed to be, and many words and phrases can only occur in certain contexts. Meanwhile, it discusses the uses of three English polarity expressions: care a damn, lift a finger, and have ever done by using the four corpora LOB, BROWN, BNC online, and CLEC and finds out that care a damn, lift a finger are used in affective contexts by native speakers but are not acquired by most Chinese learners; have ever done is also used in affective contexts by native speakers but is often used in the wrong contexts by Chinese learners. Thus, the paper concludes that Chinese learners need to understand the underlying constraints of sentence construction so as to better grasp English.
\end{abstract}

Keywords: Affective context, Polarity expression, Corpus

\section{Introduction}

How to express a meaning appropriately is the key issue in the process of second language acquisition. Second language learners tend to believe that when they know the semantic meanings of a word or a phrase, they can express the corresponding meaning of the word or the phrase correctly. However, based on the modern corpus data evidence collected from LOB, BROWN, BNC, and CLEC, this proves to be a wrong belief. Using corpus for language research is becoming mainstream (M. Halliday, 1991; G. Leech, 1993), because corpus-based approach can be efficiently applied to empirical investigations in almost any area of linguistics from a use perspective. Further, corpus-based methods can also be used to study a variety of topics within linguistics (Biber, Conrad and Reppen, 2000). Many corpus-based analyses have been made to deepen the understanding of languages in this world and those analyses have consequently been of great help in facilitating language learning as well as language teaching.

In the light of the comparative data of the above-mentioned corpus evidence, this paper aims to demonstrate that every word and phrase should be used in the right structure and right context so that they can be appropriately expressed. Sinclair (2004) states that the basic unit of meaning in a text is the lexical item, and grammar plays a role in the management of meaning, the assembly of constituents, and the componence of lexical items, which means when a certain meaning is conveyed or realized, lexical item and grammar are working integrally and simultaneously. But Sinclair also claims that grammar does not directly assist creation of meaning by grammatical choice, though it is vital for efficient communication, and the main role in meaning creation is in the lexical item.

\section{The Open Choice Principle and the Idiom Principle}

As to explaining how meaning arises from language text, Sinclair (1991) puts forwards two modes of interpretation: the Open Choice Principle and the Idiom Principle. Sinclair holds that no single principle is satisfactory enough and they complement each other. 


\section{1) The Open Choice Principle:}

This is a way of seeing language text as the result of a very large number of complex choices. At each point where a unit is completed (a word or a phrase or a clause), a large range of choice opens up, and the only restraint is grammaticalness.

This principle describes language as a "slot-and-filler" mode by envisaging text as a series of slots which have to be filled from a lexicon that satisfies local restraints. The tree structure can illustrate this mode intuitively and clearly, that is, the nodes on the tree are choice points, and items from certain word class may appear as leaves of each node.

However, it is found in practice that possible slot (or node) choices are massively reduced. In fact, native speakers of a certain language do not exercise the potential creativity of their syntactic rules. In other words, the sentences they produce are not so multifarious as they are expected according to the Open Choice Principle. Indeed, if they do so they would not be accepted as exhibiting native-like control of the language. Therefore, here comes the second principle:

2) The Idiom Principle:

It is clear that words do not occur at random in a text, and that the Open Choice Principle does not provide substantial enough restraints. We would not produce normal text simply by operating the Open Choice Principle.

This principle states that along the process of sentence construction, the openness of choice is not available to the same extent at every node (in tree structure) or in every slot, and the language user has available to him a large number of pre-constructed or semi-constructed phrases that constitute single choices, even though they appear to be analyzable into segments. The existence of the Idiom Principle, to some extent, is because the world around us is not totally full of random things and this unrandomness is reflected in our organization of language. The Idiom Principle is far more persuasive and elusive than we have allowed and expected so far. Some examples are as follows:

(a) Many phrases have an indeterminate extent.

(b) Many phrases allow internal lexical variation.

(c) Many phrases allow internal syntactic variation.

(d) Many phrases allow some variation in word order.

(e) Many uses of words and phrases attract other words in strong collocation.

(f) Many uses of words and phrases show a tendency to co-occur with certain grammatical choices.

(g) Many uses of words and phrases show a tendency to occur in a certain semantic environment.

These examples are a very concise description of the evidence that supports the idea of the Idiom Principle because it points out that the organization of language is not out of the totally open choices, but there are also some constraints deprived from the nature of the world, the rules of the language, the history of the language and the corresponding culture.

\section{The Affective-polarity Theory}

Apart from the evidence mentioned above, there is another piece of evidence which is also in support of the idea of the Idiom Principle. It is called the Affective-polarity Theory.

Edward Klima (1964, quoted in Radford, 2001) conjectures that negative words like nobody, interrogatives like whether, conditionals like if and degree expressions like too share "a common grammatico-semantic feature to be referred to as affective: in his terms, nobody/whether/if too are affective constituents. Also, there are numerous other expressions (e.g. ever, care a damn, lift a finger, at all, any, etc.) being restricted to occurring in affective contexts (the asterisk indicates ungrammatical):

(1) (a) I didn't think I would ever pass syntax

(b) *I thought I would ever pass syntax

(2) (a) He's too selfish to care a damn about what happens to you

(b) *I know that he cares a damn about what happens to you

(3) (a) I doubt whether he would lift a finger to help you

(b) *He would lift a finger to help you 
Expressions, which are restricted in this way, are referred to as polarity expressions, because they seem to have an inherent affective polarity (in the sense that they are restricted to occurring in affective contexts). In short, the Affective-polarity Theory states that there is a pre-constructed context for the occurrence of polarity expressions, namely, the affective expressions. Therefore, this is a good support for the idea of the Idiom Principle.

\section{Corpus evidence}

In this paper, four corpora (LOB, BROWN, and BNC online, and CLEC) are employed to make a comparative study of native speakers' uses of three polarity expressions (care a damn, lift a finger, have ever done) in affective contexts and those uses by the Chinese learners.

\subsection{The phrase: care a damn}

In the phrase care a damn, a damn is uttered as a curse which intensifies the mood and indicates an extent, and basic meaning of this phrase is in accordance with the word care, which means to be concerned about, and it is a colloquial expression.

In LOB corpus, no entry containing the phrase care a damn is found.

In BROWN corpus, no entry containing the phrase care a damn is found.

In BNC corpus, there are total 19 entries containing the phrase care a damn. They are as follows:

1). market did not care a damn for the long term, or strategic thinking into

2). ne minute they care a damn about you?

3). You don't care a damn about anybody but yourself.

4). I don't care a damn.

5). it don't seem to care a damn

6). ree of us didn't care a damn for the editor of The Sunday Times .

7). People don't care a damn about any of the arts.

8). You don't care a damn

9). don't even really care a damn any more, anyway.

10). She did not care a damn whether the information was protected or not

11). "Personally I don't care a damn whether you're here or not.

12). wasn't as if she ... care a damn for his opinion of her!

13). it so plain he didn't care a damn for her as a person?

14). I don't care a damn where you're going or how long you'll be;

15). $\mathrm{n}$ the road couldn't care a damn for anyone."

16). then you couldn't care a damn about it cos you couldn't do anything about it because your

17). know you don't care a damn about money.

18). don't care a damn about this place, or you, or what you own.

19). obviously doesn't care a damn for him!

Among the 19 entries, one entry (2) is in interrogative context; the others are all in negative contexts. The affective context of care a damn can be seen as interrogative and negative, and the negative context is dominating.

In CLEC corpus, there is no entry containing the phrase care a damn.

A comparison between native speakers' uses of care a damn and those of Chinese learners' is illustrated in Table 1.

\subsection{The phrase: lift a finger}

The phrase lift a finger, which is usually used in negative context, means not to help to do something, because she/he is usually lazy.

In LOB corpus, only one entry is found: 
1). nor did the Soviet Government lift a finger to succor them.

In BROWN corpus, no entry containing the phrase lift a finger is found.

In BNC corpus, 15 entries are found. They are as follows:

2). Now you're not to lift a finger, my dear, is she, Lilian?

3). before a man can lift a finger (if you'll forgive the phrase).

4). Doesn't lift a finger, does David Never a handsturn from him, believe me.

5). But Mum didn't lift a finger to help and gave as good as she got.

6). no one is going to lift a finger of complaint even, until the case is watertight.

7). -in-law I wouldn't lift a finger to help him.

8). weren't prepared to lift a finger to help.

9). I wasn't to let you lift a finger about the house.

10). Pickles never has to lift a finger

11). She'd not lift a finger in this house, she wouldn't.

12). is not prepared to lift a finger to help secure a future for steel production in Scotland?

13). niele is too busy to lift a finger, like the rest of you.

14). I'm not allowed to lift a finger.

15). Didn't lift a finger Dave to put it out

16). didn't even have to lift a finger because the man or her servants would do all this for her.

Among the 15 entries, almost all the other entries, lift a finger is used with negative affective expressions except the second one.

In CLEC, no entry containing lift a finger is found.

The comparison between native speakers' uses of the phrase lift a finger and Chinese learners' uses of it is illustrated in Table 2.

\subsection{The structure: have ever done}

According to Collins (Cobuild) English Language Dictionary (1995), the word ever in the structure have ever done can have two meanings. One is at any time and the other is all the time. When ever means at any time, have ever done should be used in the affective context, that is, in negatives, in questions, in conditional structures, with words expressing uncertainty such as "doubt", with superlatives and in comparisons. When ever means all the time, have ever done is used straightforwardly. The following are the examples.

First, when ever means at any time, have ever done should be used with affective expressions (all the examples are selected from BROWN, $\mathrm{LOB}$ and $\mathrm{BNC}$ online corpus).

\section{In negatives:}

1). mple reason that such appeals have hardly ever been made. Diocesan authorities generally ha

2). rites or comets. No meteorites have ever been recovered from paleoexplosion craters,

3). would not, he said ... once, have ever come about if Mrs. Meeker had only seen fit

4). I cannot say that I have ever known of a young lady dying of

5). robably a fact that few people have ever thought about, but a fact nonetheless, that nights are

6). scatters of flints, and very few have ever been scientifically examined.

7). Few women artists have ever become household names.

8). ld not have been possible ...to have ever occurred at all, if it were encumbered by the constra.

9). ity, perhaps --; so few people have ever met me, so many seem anxious to do so

10). hough none of these methods have ever proved completely successful, the idea of having win

\section{In questions:}

1). How many of these girls ... have ever heard of the Incas of Peru? 
2). d, "I was at Ryusenji today. Have you ever been to Ryusenji"? No one had. "Well, it's a

3). dess of death, is worshiped. Have you ever heard of thuggee? Nuf sed.... But it is the

4). the colors of it, didn't you? Have you ever seen anything like it around here"? "Snak

5). her a lewd, winking effect. "Have you ever tried to reason with an Eskimo"? she asked,

6). aps you couldn't do that but have you ever tried to see what you could do with a hunk

7). brought into being. Have you ever heard talk concerning three men who $\mathrm{N}$

8). he said sombrely: Have you ever heard of a punishment called the cord

9). reply to the question, "Have you ever had crying attacks?" was

\section{In conditional structures:}

1). If you have ever considered setting up a photographic studio then you will know that there is

2). If you have ever stood on a sheep farmer's hillside, as I have done many times in the Western

3). If you have ever stood on a sheep farmer's hillside, as I have done many times in the Western

\section{Expressing uncertainty:}

1). They have asked if Jewish women have ever really been included in the Jewish covenant.

2). $r$ I don't know whether any of you have ever been into the little private chapel, St William's

3). ell the doctor if any close relatives have ever had similar problems

4). I doubt if Bob Kernohan and I have ever agreed on anything except personal integrity

5). rs would tell B16 158 us if they have ever suffered injury or damage from a defe

\section{With superlatives and comparisons:}

1). leans was one of the hardest courses I have ever played.

2). The best organisation that we have ever experienced was the Great Ormond Street Hospi

3). ced: He is more agreeable than I have ever seen him.

4). hich is quite simply the best that I have ever seen and which appeals at many levels: intellec

5). nd toughest question young lovers have ever asked: How can you be sure? “Aren't you

6). series is incomparably the finest I have ever had the pleasure of witnessing.

7). finest "classical" ballet company I have ever seen, and the production of the Petipa-Tscha

8). ces were as beautiful as anything I have ever seen- they rival the New York Rockettes for

9). five of the longest days I have ever lived through. We expect

10). most striking-looking men that I have ever seen. He was you $j$

Second, when the phrase have ever done is not used in affective context, the word ever means all the time, and this kind of use is very rare according to native speakers' intuition. Some examples are as follows:

1). Those who hold, and those who are without property, have ever formed distinct interests in society."

2). In 12 years, all the Government have ever done, and all they are doing now, is hope that the increase in consumer demand will eventually refloat the economy

3). even modern socialism, as they exist or have ever existed in theory or in practice. Consider t

Among the 82 sentences selected from BROWN, LOB, and BNC corpora, they contain native speakers' uses of the structure have ever done, and most of them are constructed in the context of comparison, as is shown in Table 3.

However, Chinese learners' uses of the structure have ever done seems to differ greatly from native speakers'. The most obvious mistake they make is that they don't use have ever done in affective context, that is, they use it straightforwardly. But the meaning they want to convey is have done something at any time, instead of have done something all the time. This kind of expression confuses native speakers very much.

In order to illustrate the difference more clearly, the variances (has ever done/had ever done) of the structure have ever done are also selected to make a comparison. The phrase have ever done is the basic form of the variances, and the basic form and variances differ only in syntactic features such as tense and number, which do 
not affect the semantic meanings of the structure. The entries searched in CLEC are as follows:

\section{In negatives:}

1). Time goes on. Yet no changes have ever taken place. The situation is always the same,

2). then none of the states that has ever existed is civilized, including US, UK, Japan and many o

\section{In questions:}

1). Have you ever brought clothes made ø from synthesis fiber while marked

2). Have you ever experienced that in the

3). Have you ever heard a saying in Buddhist Scripture: Better save one life than build up a seve $f$

4). Have you ever seen sunflowers? I'm sure you have. They are growing here $ø$ and there, before

5). Have you ever seen the film --Lion King. I have seen on the Spring Festival. This film is ve

6). Have you ever seen the film--Aladdin. But I have never seen it. Because ø it's too late when I h

\section{In conditional structures:}

1). good, and evil with evil. If one has ever commit certain crime and escape by chance.

2). and able to anybody if only he has ever watch any program either sadism or

3). he knife. They said if the boy had ever used a switch knife, he would never stabbed

Expressing uncertainty: no entry has been found.

\section{With superlatives and comparisons:}

1). which is the most beautiful country you have ever seen? they are always surprised if

2). $\mathrm{h}$ two lashes. It's said that people who have ever got lashes, never commit any

3). the mental area is that the person who had ever been crime will lose all standing and

4). ho's taller than you are. And one who has ever had any experience with switch kni

5). got used to knife fight and anyone who has ever used a switch knife would use it

6). using knife. However, anyone who's ever used a switch knife will use it

7). than you are. Furthermore, anyone who's ever used a switch knife would never

8). is hand above his shoulder. Anyone who's ever used a switch knife would never ha

The other 20 sentences searched from CLEC are all bad sentences, in which the structure have ever done is constructed straightforwardly, but the meaning that the learners want to convey is have done something all the time. The following are some examples:

1) We often hear about fake commodities, and perhaps you have ever bought some fake commodities.

2) As a student, I often use recharge battery. But I have ever bought a fake one, it can't be recharged.

3) I will take the active part in the activities to know the society. I have ever cleaned the streets near our school with many students, and I have ever visited some factories

4) Through these paths, we can contact various of people and something that we have ever contact before.

5) I have ever heard something interesting about two presidents (I don't remember if this is their position)

6) I have ever received shorthand training. I can type 40 words per minute. I am familiar with a

Table 4 illustrates Chinese learners' uses of the structure discussed above.

According to Table 3 and Table 4, it can be clearly seen that there is a sharp contrast between native speakers' uses of the structure have ever done and those of Chinese learners'. It seems that Chinese learners don't know the structure have ever done should be put into affective context to mean have done something at any time nor do they know have ever done can mean have done something always or all the time when it is used straightforwardly. However, according to native speakers' uses, only $3.7 \%$ of the entries searched in this study convey the meaning have done something all the time, and the other $96.3 \%$ mean have done something at any time. Therefore there is an overwhelming impression for learners that ever means at any time in the structure have ever done, and with the help of the grammar-translation teaching methodology, ever is often translated as cengjing in Chinese, which means at any time, so it is natural for Chinese learners to overlook the affective 
context.

\section{Conclusion}

In this comparative study, it can be seen that there is a significant contrast between native speakers uses of the three polarity expressions: care a damn, lift a finger and have ever done and those of the Chinese learners'. For the first two phrases, no entry can be searched in CLEC, which indicates that they are not acquired by most Chinese learners, and there are also very few entries found in BROWN and LOB, which shows that the two often appear in colloquial expressions. As for the structure have ever done, Chinese learners misuse it a lot.

The inspiration of this study is that Chinese learners should realize that language form and language meaning are closely connected and interact with each other. For the Chinese learners who try to have a good command of English language, it is far from enough for them to know the semantic meanings of the words or phrases only. More importantly, the Chinese learners need to understand the underlying constraints of sentence construction. In the meantime, corpora can provide substantive and concrete examples of the language output of native speakers, which is very important and helpful in language teaching and learning.

\section{References}

Biber, Douglas, Conrad, Susan \& Reppen, Randi. (2000). Corpus Linguistics. Beijing: Foreign Language Teaching and Research Press, pp. 11.

BNC online. Retrieved from: http://www.natcorp.ox.ac.uk/

Collins (Cobuild) English language dictionary. (1995). London: HarperCollins Publishers Ltd, pp. 567-568.

Halliday, M. A. K. (1991). Corpus studies and probabilistic grammar. In K. Aijmer \& B. Altenberg (Eds.), English corpus linguistics: Studies in honor of Jan Svartvik (pp. 30-43). London: Longman Group Ltd.

Leech G. (1993). Corpus Annotation Schemes. Literary and Linguistic Computing. Vol. 8, No. 4. Oxford: Oxford University Press, pp 275-281.

Radford, Andrew. (2001). Syntactic theory and the structure of English: A minimalist approach. Cambridge: Cambridge university press, pp. 255-256.

Sinclair, John. (1991). Corpus, Concordance, Collocation. Oxford: Oxford University Press, 186-188.

Sinclair, John. (2004). Progress and prospects in corpus linguistics. Modern Foreign Languages, 27(2), 113-115.

Table 1. A comparison of the use of the phrase care a damn in different corpora

\begin{tabular}{|c|c|c|c|c|}
\hline Node & \multicolumn{3}{|c|}{ Native speakers' uses } & Chinese learners' uses \\
\hline \multirow{2}{*}{ Care a damn } & LOB & BROWN & BNC & CLEC \\
\cline { 2 - 5 } & occurrences & Occurrences & occurrences & occurrences \\
\hline & 0 & 0 & 19 & 0 \\
\hline Total & \multicolumn{3}{|c|}{19} & 0 \\
\hline
\end{tabular}

Table 2. A comparison of the use of the phrase lift a finger in different corpora

\begin{tabular}{|c|c|c|c|c|}
\hline Node & \multicolumn{3}{|c|}{ Native speakers' uses } & Chinese learners' uses \\
\hline \multirow{3}{*}{ Lift a finger } & LOB & BROWN & $\mathrm{BNC}$ & CLEC \\
\hline & occurrences & occurrences & occurrences & occurrences \\
\hline & 0 & 0 & 15 & 0 \\
\hline Total & \multicolumn{3}{|c|}{15} & 0 \\
\hline
\end{tabular}


Table 3. Native speakers' uses of the phrase have ever done

\begin{tabular}{|c|c|c|c|c|c|c|}
\hline Meanings & \multicolumn{5}{|c|}{ ever means at any time } & $\begin{array}{c}\text { ever means all } \\
\text { the time }\end{array}$ \\
\hline $\begin{array}{l}\text { Affective } \\
\text { context }\end{array}$ & $\begin{array}{c}\text { In } \\
\text { negatives }\end{array}$ & $\begin{array}{c}\text { In } \\
\text { questions }\end{array}$ & $\begin{array}{c}\text { In } \\
\text { conditional } \\
\text { structures }\end{array}$ & $\begin{array}{l}\text { Expressing } \\
\text { uncertainty }\end{array}$ & $\begin{array}{c}\text { With } \\
\text { superlatives } \\
\text { and } \\
\text { comparisons }\end{array}$ & $\begin{array}{c}\text { Used } \\
\text { straightforwardly }\end{array}$ \\
\hline BROWN & 4 & 8 & 0 & 1 & 18 & 1 \\
\hline LOB & 1 & 3 & 0 & 1 & 7 & 0 \\
\hline $\mathrm{BNC}$ & 6 & 1 & 2 & 4 & 23 & 2 \\
\hline Total & 11 & 12 & 2 & 6 & 48 & 3 \\
\hline percentage & $13.4 \%$ & $14.6 \%$ & $2.4 \%$ & $7.3 \%$ & $58.5 \%$ & $3.7 \%$ \\
\hline
\end{tabular}

Table 4. Chinese learners' uses of the phrase have ever done

\begin{tabular}{|c|c|c|c|c|c|c|}
\hline Meanings & \multicolumn{5}{|c|}{ ever means at any time } & $\begin{array}{l}\text { ever means all } \\
\text { the time }\end{array}$ \\
\hline $\begin{array}{l}\text { Affective } \\
\text { context }\end{array}$ & $\begin{array}{c}\text { In } \\
\text { negatives }\end{array}$ & $\begin{array}{c}\text { In } \\
\text { questions }\end{array}$ & $\begin{array}{c}\text { In } \\
\text { conditional } \\
\text { structures }\end{array}$ & $\begin{array}{l}\text { Expressing } \\
\text { uncertainty }\end{array}$ & $\begin{array}{c}\text { With } \\
\text { superlatives } \\
\text { and } \\
\text { comparisons }\end{array}$ & $\begin{array}{c}\text { Used } \\
\text { straightforwardly }\end{array}$ \\
\hline CLEC & 2 & 6 & 3 & 0 & 8 & 0 \\
\hline percentage & $5.1 \%$ & $15.4 \%$ & $7.7 \%$ & 0 & $20.5 \%$ & 0 \\
\hline
\end{tabular}

Among the above entries searched in CLEC, 20 of them contain a wrong usage of the phrase have ever done, which account for $51.3 \%$. 